Hydrol. Earth Syst. Sci., 17, 3159-3169, 2013

www.hydrol-earth-syst-sci.net/17/3159/2013/

doi:10.5194/hess-17-3159-2013

(C) Author(s) 2013. CC Attribution 3.0 License.

\title{
Application of a model-based rainfall-runoff database as efficient tool for flood risk management
}

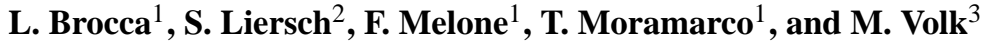 \\ ${ }^{1}$ Research Institute for Geo-Hydrological Protection, National Research Council, Perugia, Italy \\ ${ }^{2}$ Potsdam Institute for Climate Impact Research (PIK), Potsdam, Germany \\ ${ }^{3}$ UFZ - Helmholtz Centre for Environmental Research, Department Computational Landscape Ecology, Leipzig, Germany
}

Correspondence to: L. Brocca (luca.brocca@irpi.cnr.it)

Received: 22 January 2013 - Published in Hydrol. Earth Syst. Sci. Discuss.: 18 February 2013

Revised: 30 June 2013 - Accepted: 3 July 2013 - Published: 6 August 2013

\begin{abstract}
A framework for a comprehensive synthetic rainfall-runoff database was developed to study catchment response to a variety of rainfall events. The framework supports effective flood risk assessment and management and implements simple approaches. It consists of three flexible components, a rainfall generator, a continuous rainfallrunoff model, and a database management system. The system was developed and tested at two gauged river sections along the upper Tiber River (central Italy). One of the main questions was to investigate how simple such approaches can be applied without impairing the quality of the results. The rainfall-runoff model was used to simulate runoff on the basis of a large number of rainfall events. The resulting rainfallrunoff database stores pre-simulated events classified on the basis of the rainfall amount, initial wetness conditions and initial discharge. The real-time operational forecasts follow an analogue method that does not need new model simulations. However, the forecasts are based on the simulation results available in the rainfall-runoff database (for the specific class to which the forecast belongs). Therefore, the database can be used as an effective tool to assess possible streamflow scenarios assuming different rainfall volumes for the following days. The application to the study site shows that magnitudes of real flood events were appropriately captured by the database. Further work should be dedicated to introduce a component for taking account of the actual temporal distribution of rainfall events into the stochastic rainfall generator and to the use of different rainfall-runoff models to enhance the usability of the proposed procedure.
\end{abstract}

\section{Introduction}

The increasing number and intensity of floods and flash flood events has caused environmental problems, taking a high human and economic toll (Smith and Ward, 1998; Villarini et al., 2010). Consequently, numerous new tools and programs for flood forecasting systems and risk management plans have been developed in the concerning period (Damle and Yalcin, 2007; Chao et al., 2008; Cloke and Pappenberger, 2009; Reggiani and Weerts, 2008; Romanowicz et al., 2008; Tiwari and Chatterjee, 2010; Villarini et al., 2010). In fact, with the growing evidence of flooding, decision makers need to take actions for addressing the disaster risk management through a reliable flood forecasting system (FFS hereafter) to respond to weather-induced catastrophic events. In this context, it should be aimed at a right equilibrium between the need to achieve an accurate forecast and to develop a correct analysis of the rainfall spatial distribution, runoff formation and flood routing. Efforts in this direction have been made in the last decades. FFSs have been operating in the US since 1993, when distributed flash flood warning systems also capable of utilizing weather radar data started to be tested (Georgakakos, et al., 1993) and the meteorologicalhydrological models were coupled for simultaneous rainfall and flow prediction in operational use (Bae et al., 1995). The target is to reduce the impact of flooding by providing early warnings several days ahead (de Roo et al., 2003). Therefore, at FFS there is a demand to achieve a lead time longer than the natural time response of river catchment. At the purpose, the nowcasting techniques $(0-6 \mathrm{~h})$ or the quantitative precipitation forecasts (QPFs) provided by numerical 
weather prediction (NWP) models (1-4 days) are fundamental tools and should represent the core of an FFS (Barbetta et al., 2012). The NWP models can be linked to continuous hydrological modelling which has the potential advantage to explicitly represent the dependence of runoff response on antecedent soil moisture conditions of basins (Brocca et al., 2008a). Therefore, FFSs would represent a fundamental component of preparedness plans for preventing the disastrous flood events (Werner et al., 2005). However, large uncertainties are still involved in precipitation forecasts due to limited understanding on complex atmospheric processes. And although the use of NWPs is becoming a widespread activity, many further improvements are required (Cloke and Pappenberger, 2009). Beside the issue of rainfall spatial variability forecast, rainfall-runoff transformation to produce river discharge predictions is another source of uncertainty (Beven and Binley, 1992; Gabellani et al., 2007; Vaze et al., 2010; Van Steenbergen and Willems, 2012). Moreover, decision makers demand for well-designed, but simple FFSs. On the one hand, such FFSs should have the advantage of running with less computer power over the complex systems. On the other hand, they should be able to incorporate the uncertainty estimation in the forecast to enhance the reliability of both the forecasting and warning system in real-time flood management. In fact, quantifying uncertainty within the flood forecasting would enable the authorities to set riskbased criteria for flood warning, furnish information for making rational decisions and offer potential for additional economic benefits of forecasts to every rational decision maker (Krzysztofowicz, 2001).

In this context, this paper proposes a comprehensive rainfall-runoff database (RR-DB) to be used as an integrated tool of an FFS which takes the discharge forecast uncertainty into account. The RR-DB is based on the coupling of a stochastic rainfall and temperature generator tool and a continuous hydrological model (Asquith et al., 2004; Liersch and Volk, 2008). This coupling enables the simulation of both the soil moisture conditions of the basin and the corresponding streamflow (Camici et al., 2011). The results of these simulations are stored in the database and include large numbers of rainfall-runoff scenarios which allow for the uncertainties of rainfall forecasts and soil moisture conditions of the basin. Consequently, the decision maker can easily inquire which stream flow values might result from defined rainfall amounts or vice versa. The decision maker will retrieve the discharge hydrograph scenarios without having to run any kind of coupled models - this is advantageous with regard to considerable time savings to issue warnings. The system has been developed and tested at two gauged river sections along the upper Tiber River (central Italy). The case study area has been and still is affected by severe flooding events that caused considerable damages in the region.

The paper is organized as follows: Sect. 2 outlines the method for developing the RR-DB along with an overview of the rainfall and temperature scenario generator and the continuous hydrological model, which are used for developing the database. Furthermore, Sect. 2 underlines the structure of the RR-DB and highlights the cluster analysis adopted for the simulated streamflow and corresponding initial soil moisture data. Section 3 describes the study area. Section 4 explains the RR-DB implementation while its employment for the two river sites is described in Sect. 5. Finally, conclusions are drawn in the last Sect. 6.

\section{Methods}

The operational system of the RR-DB consists of three main model components: (1) a weather generator (rainfall and temperature), (2) a continuous rainfall-runoff model, and (3) a relational database management system (RDBMS) used to store and manage simulation data.

The steps required to develop the RR-DB are:

1. Generation of $N$ flood-relevant rainfall events accompanied by $N$ temperature scenarios.

2. Calibration and validation of a continuous rainfallrunoff model based on observed rainfall, temperature, and runoff data.

3. Identifying classes of season-specific initial discharge $(Q)$ and antecedent catchment wetness conditions (AWC), respectively. These preconditions were obtained from runoff simulations based on the historical time series by applying a clustering approach $(k$ means algorithm).

4. For each selected rainfall event and initial catchment condition in terms of discharge and wetness, the rainfall-runoff model is used to simulate the discharge hydrograph at the basin outlet. Therefore, the database consists of $N \times Q \times$ AWC discharge records representing the response of the basin at different storms acting under different initial discharge and wetness conditions.

The following subsections in this chapter describe in detail the specific models used in this study.

\subsection{Stochastic rainfall generator}

The Neyman-Scott Rectangular Pulse (NSRP) model (Cowpertwait et al., 1996) was used to generate $N$ half-hourly rainfall events. The temporal resolution of the data was selected based on the available rainfall data and smaller than the catchment response time (about $6 \mathrm{~h}$ ). The total duration of the event has to be chosen in such way that the whole storm is encompassed (i.e., without stopping before the end). The NSRP model is characterized by a flexible structure in which the model parameters broadly relate to underlying physical features observed in rainfall fields. Full details of the NSRP may be found by Cowpertwait et al. (1996), therefore only 
a brief description of the model is given here. The NSRP model supposes that each storm origin follows a Poissonian process. Then, a random number of cell origins is displaced from the storm origins by exponentially distributed distances. A rectangular pulse is associated with each cell origin, with duration and intensity expressed by two other independent random variables assumed exponentially distributed. The total intensity at any point in time is then the sum of all the active cell intensities at that particular point.

The NSRP model has a total of five parameters that can be estimated by minimizing an objective function evaluated as the weighted sum of the normalized residuals between the statistical properties of the observed time series and their theoretical expression derived from the model. As showed by previous studies (Rodriguez-Iturbe et al., 1987; Cowpertwait, 1991a, b), the main feature of the model is its ability to preserve statistical properties of a rainfall time series over a range of time scales.

\subsection{Stochastic temperature generator}

The rainfall scenarios are accompanied by temperature scenarios generated by using the fractionally differenced ARIMA model (FARIMA) (Montanari et al., 1997). Unlike classical ARIMA models that are a powerful tool for modelling stationary time series, the FARIMA models are able to fit autocorrelation functions characterized by a slow decay, suggesting the presence of a long-term persistence. This dependence, namely the Hurst effect (Hurst, 1951), has been detected in many temporal series of hydrological data and very often in air temperature series (Moretti and Montanari, 2008). The procedure for the implementation of the FARIMA model is not straightforward, particularly in the identification phase for the preliminary evaluation of model parameters. The method employed in this study is the one suggested by Montanari et al. (1997). We note that the correlation between rainfall and temperature is not taken into account as we found a non-significant correlation between the two variables in the observed data.

\subsection{Continuous rainfall-runoff model}

The "Modello Idrologico SemiDistribuito in continuo" (MISDc, Brocca et al., 2011a) is selected as continuous rainfall-runoff model. The model was developed for the simulation of flood events at half-hourly time scale and consists of two components: the first is a soil water balance model (Brocca et al., 2008a) that simulates the soil moisture temporal pattern and sets the initial conditions for the second component, which is an event-based rainfall-runoff model for flood hydrograph simulation. The two models are coupled through a simple linear relationship that was derived from an intense monitoring activity of soil moisture and runoff over experimental catchments located in central Italy (Brocca et al., 2009). The model incorporates a limited number of parameters and it is characterized by low computational efforts which make it very attractive for the hydrological practice. For that, the MISDc model can be conveniently adopted for the generation of long discharge time series (e.g. 1000 or more years). For a detailed description of the model the reader is referred to Brocca et al. (2011a) and Camici et al. (2011). MISDc has already been successfully applied in several catchments in Italy (Brocca et al., 2010, 2011a; Camici et al., 2011) and across Europe (Brocca et al., 2011b). In this study, we used the lumped version of the model and added a simple component for the simulation of baseflow in order to simulate the discharge during non-flood conditions (Brocca et al., 2008b, 2011b). Specifically, a nonlinear power function between the soil moisture storage of the model and the baseflow is adopted. Finally, we note that the model is currently employed operational within the Civil Protection Centre of the study region for real-time flood forecasting in the study area. It is freely available at the following website: http://hydrology.irpi.cnr.it/people/l.brocca.

\subsection{Relational DataBase Management System (RDBMS)}

The RDBMS consists basically of three tables: (1) the weather scenarios (rainfall and temperature), (2) catchment preconditions at time step $t_{0}$ to initialize the rainfall-runoff model, and (3) runoff scenarios.

\subsubsection{Precondition table}

Usually, rainfall-runoff models require rather long "warmup" periods before they provide reasonable results. In order to avoid this, the runoff simulations based on each rainfall/temperature scenario are starting with different initial model states. These states represent a variety of possible catchment saturation preconditions (wet to dry) at time step zero $\left(t_{0}\right)$. The parameters required for model initializations are the antecedent wetness index $\left(\mathrm{AWC}_{0}\right)$ and initial discharge $\left(Q_{0}\right)$. These combinations are stored in the catchment precondition table in the database. This table could show, for instance, that the first combination is $Q_{0}=30 \mathrm{~m}^{3} \mathrm{~s}^{-1}$ and $\mathrm{AWC}_{0}=0.8$, that the second combination is $Q_{0}=30 \mathrm{~m}^{3} \mathrm{~s}^{-1}$ and $\mathrm{AWC}_{0}=0.9$, and so on. $Q \times$ AWC precondition combinations for each rainfall scenario were used in this study. Thus, $N \times Q \times$ AWC runoff scenarios are stored in the database.

\subsubsection{Selecting runoff scenarios}

The $k$ means (Hartigan and Wong, 1979) clustering method was used to generate a number of meaningful classes of $Q$ and AWC combinations for each month. This classification allows identifying antecedent wetness condition ranges that correspond to season-specific discharge values. In order to select runoff scenarios from the database, information on current and future events are required. Current information is 


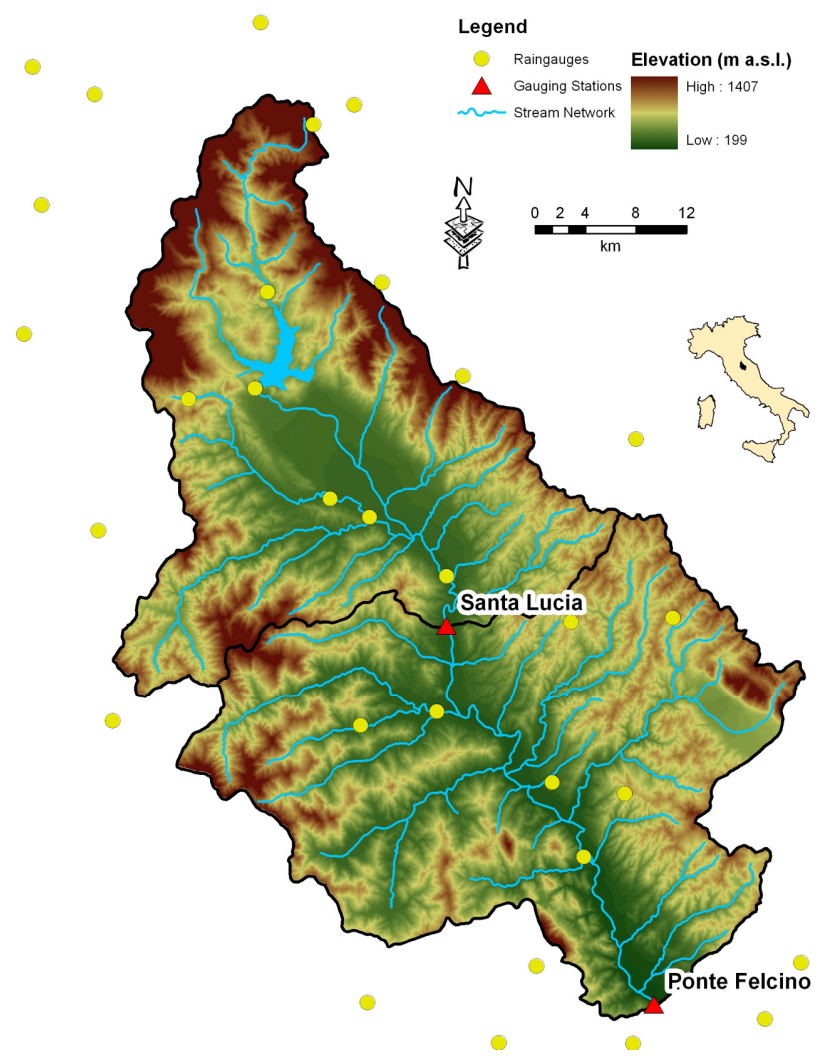

Fig. 1. Terrain conditions of the Upper Tiber River Basin and location of the hydrometeorological monitoring network.

the observed actual discharge $Q_{0}$ at the gage site and the antecedent wetness condition $\left(\mathrm{AWC}_{0}\right)$. The range for the latter is obtained from the seasonal classification described above. Information about the future is determined by the weather forecast representing a range of expected rainfall depths. Thus, $Q_{0}, \mathrm{AWC}_{0}$ of current month, along with rainfall forecasts are used as criteria to select runoff scenarios from the database. In order to account for uncertainties in observed discharge measurements at time step $t_{0}$, the range of initial $Q_{0}$ values in the precondition table that bracket the current observation is used.

It is worth noting that the RR-DB was finalized to support applied flood risk management with a useful and simple tool, providing a large set of flood-relevant rainfall-runoff simulations (Liersch and Volk, 2008). Once the RR-DB has been developed for a gauged river site, it can be applied by users without or with limited hydrologic modelling expertise.

\section{Study area}

The study area is situated in an inland region of central Italy and it includes two sub-catchments of the Upper Tiber River Basin: Tiber at Santa Lucia $\left(935 \mathrm{~km}^{2}\right)$ and Ponte Felcino
Table 1. Performance of the MISDc model in the calibration and validation periods for Santa Lucia and Ponte Felcino river sections (NSE: Nash-Sutcliffe efficiency, ANSE: NSE for high flow conditions, $R^{2}$ : determination coefficient).

\begin{tabular}{lcccccccc}
\hline & \multicolumn{3}{c}{$\begin{array}{c}\text { Calibration period } \\
(2000-2005)\end{array}$} & & \multicolumn{3}{c}{$\begin{array}{c}\text { Validation period } \\
(2006-2010)\end{array}$} \\
\cline { 2 - 4 } \cline { 7 - 9 } Gauge & NSE & ANSE & \multirow{2}{*}{$R^{2}$} & & NSE & ANSE & $R^{2}$ \\
\hline Santa Lucia & 0.758 & 0.910 & 0.793 & & 0.843 & 0.889 & 0.849 \\
Ponte Felcino & 0.830 & 0.902 & 0.850 & & 0.848 & 0.938 & 0.860 \\
\hline
\end{tabular}

$\left(2035 \mathrm{~km}^{2}\right)$, respectively (see Fig. 1). The main features of the two investigated catchments are reported in Table 1.

The climate is Mediterranean with mean annual precipitation of about $950 \mathrm{~mm}$, ranging from $700 \mathrm{~mm}$ at lower elevations to $1600 \mathrm{~mm}$ along the ridges. Higher monthly precipitation values are generally observed during the autumn-winter period when widespread rainfalls cause flood events in the region. Mean annual temperature ranges between $5.5^{\circ} \mathrm{C}$ at higher elevations to $16^{\circ} \mathrm{C}$ in the lowlands. Snowfall represents a low percentage of precipitation and is unusual and ephemeral at altitudes below $500 \mathrm{~m}$ a.s. 1 .

In the study area, a dense hydro-meteorological monitoring network ( 1 station every $150 \mathrm{~km}^{2}$ ) has been operating for more than $25 \mathrm{yr}$ and the data are recorded with a time interval of $30 \mathrm{~min}$. With regard to runoff data, the two gauging stations are equipped with remote ultrasonic water level gauges, while the measurements of flow velocity are performed by current meter from cableways also during high floods - thus warranting a reliable rating curve. For this study eleven years of rainfall, temperature and discharge data recorded from 2000 to 2010 were considered.

Three significant flood events occurred in this period that caused widespread flooding (Berni et al., 2009a, b; Brocca et al., 2011a). Specifically, the flood events occurred in November 2005, December 2008 and January 2010. They provoked significant economic losses and constitute the main test-cases for the application of the RR-DB.

\section{Rainfall-runoff database implementation}

In the following, the analyses performed for the two selected basins are reported. For each basin, the estimation of the parameters of the rainfall and temperature stochastic models, the calibration/validation of the rainfall-runoff model, and the analysis of their performance is described.

\subsection{Synthetic weather scenario generation}

\subsubsection{Rainfall generator}

For each basin the mean areal rainfall series, computed through the Thiessen polygon method, were assumed as the "observed" lumped rainfall series. In accordance with 
(A)

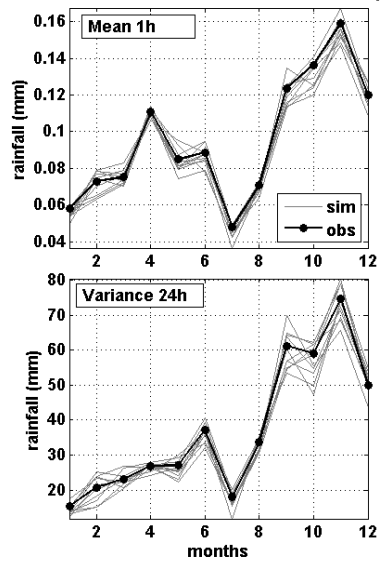

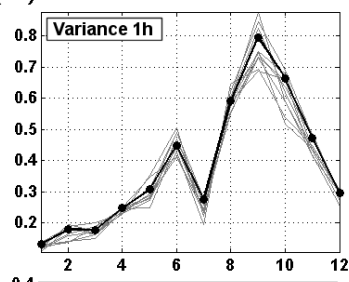
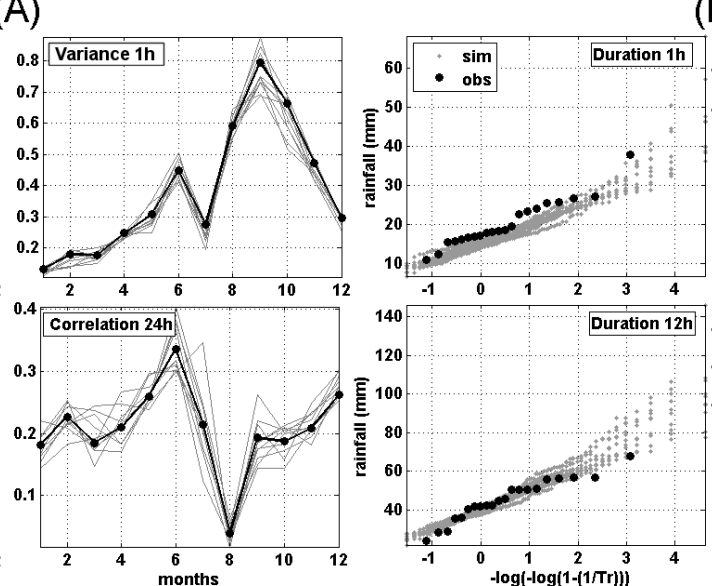

(B)
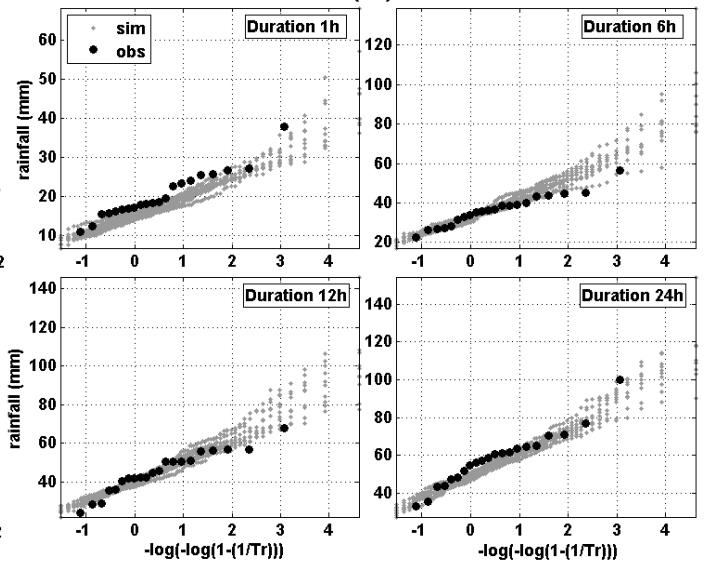

Fig. 2. Comparison of the observed, obs, and simulated, sim, time series generated through the NSRP model (10 runs) for Santa Lucia basin considering: (A) the monthly statistical properties, and (B) the rainfall annual maxima values for durations between 1 and 24 .

previous studies (e.g. Camici et al., 2011), the NSRP model calibration was carried out for each month of the year on the basis of four sampling statistics at different temporal aggregation levels: the hourly mean, the hourly and daily variance and the lag-one autocorrelation of daily data. Therefore for each month, the NSRP parameters were estimated by minimizing a weighted sum of normalized residuals between the sample and theoretical moments. The weights were assigned as in Camici et al. (2011) with greatest values for the hourly mean and the lag-one autocorrelation of daily data (Cowpertwait et al., 1996).

In Fig. 2a, the observed and simulated monthly values of the most significant statistical properties for the mean areal rainfall series are plotted for Santa Lucia basin as an example. The curves show a substantial agreement for all the statistical properties, also for those not considered in the calibration process. The frequency of annual maximum rainfall for four selected durations (between 1 and $24 \mathrm{~h}$ ) of the same basin is shown in Fig. 2b. It becomes obvious that the observed extreme values are fairly well reproduced by the NSRP model as well, except for a slight underestimation of hourly values and overestimation of $6 \mathrm{~h}$ and $12 \mathrm{~h}$ values. Therefore, it can be concluded that the NSRP model can be used to represent both the observed statistical properties and the extreme values. For Ponte Felcino basin, similar results are obtained (not shown for brevity).

After its calibration, the NSRP model was used with the optimal parameter set to simulate $1000 \mathrm{yr}$ of continuous halfhourly rainfall values. From this time series, the rainfall events were extracted by adopting a specific procedure. A flood-relevant rainfall event was defined if the total rainfall is greater than $10 \mathrm{~mm}$; each event is distinguished from another one if a total rainfall less than $1 \mathrm{~mm}$ occurred for at least $10 \mathrm{~h}$. Following this procedure, $N=10000$ rainfall events were extracted for the two basins and used for building the

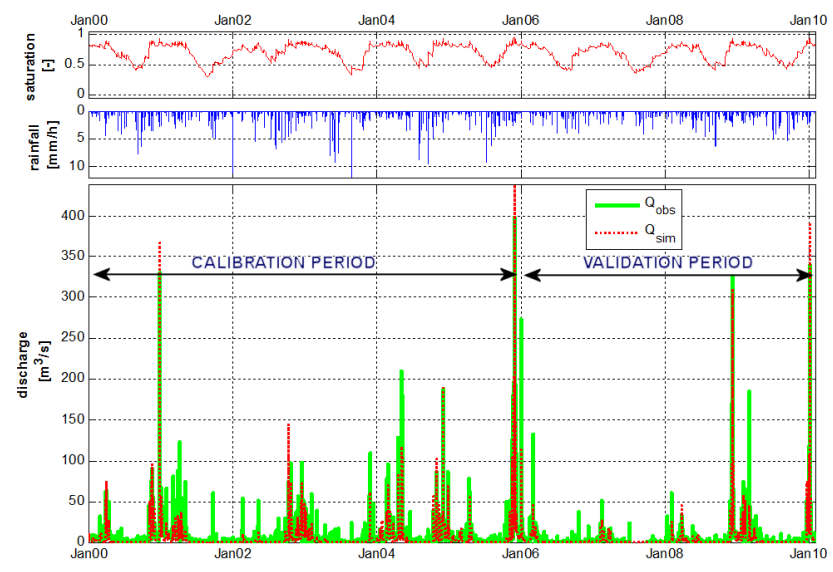

Fig. 3. Comparison of the observed, $Q_{\text {obs }}$, and simulated, $Q_{\text {sim }}$, discharge (lower panel) for the calibration (a) and validation (b) periods at Santa Lucia river section. The temporal pattern of soil saturation and rainfall is also shown in the upper panels.

RR-DB. As none of the selected events exceeded the foreseen five days, they were extended with zero value rainfall values.

\subsubsection{Temperature generator}

The procedure for the generation of temperature time series requires a preliminary analysis of the observed data in order to detect and eliminate the seasonal variability. Specifically, the seasonal non-stationarities in the mean as well as the variance were handled by externally estimating the first two moments and then normalizing to a zero mean, unit variance process (Bras and Rodriguez-Iturbe, 1985). This methodology was applied to the areal mean of the observed mean daily temperature series, extracted from the half-hourly data. Then, the FARIMA model was calibrated and used to generate 

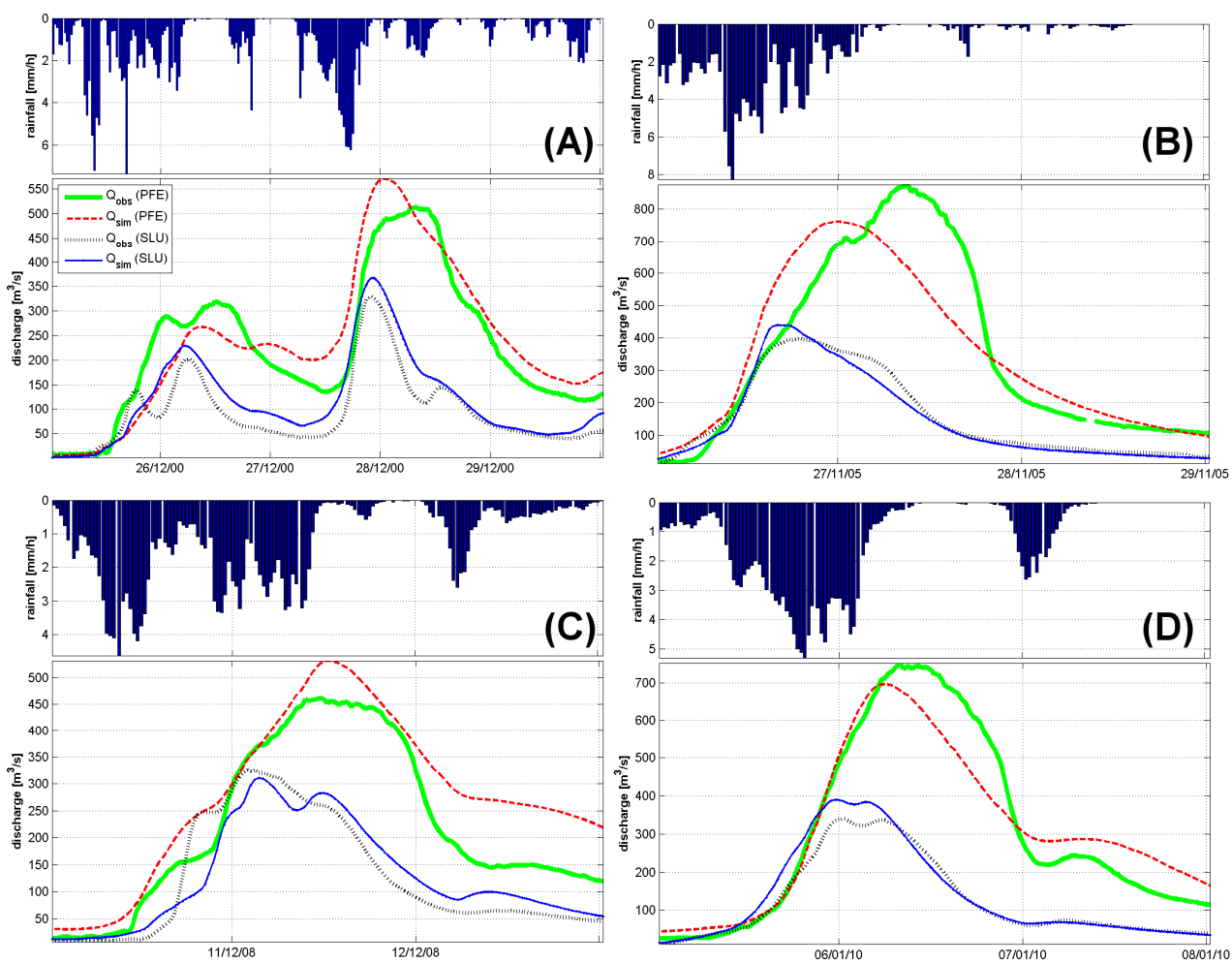

Fig. 4. Comparison of the observed, $Q_{\mathrm{obs}}$, and simulated, $Q_{\mathrm{sim}}$, discharge for the four largest flood events occurred in the study period for Santa Lucia and Ponte Felcino river sections: (A) December 2000, (B) November 2005, (C) November 2008, and (D) January 2010. The mean areal rainfall pattern for Ponte Felcino basin is also shown.

$1000 \mathrm{yr}$ of synthetic daily mean temperature values. Finally, the synthetic series were disaggregated at half-hourly temporal resolution using a sine-cosine wave function (Hashemi et al., 2000). Half-hourly temperature values were accompanied to rainfall values by considering the same synthetic dates previously obtained in the extraction of rainfall events.

\subsection{MISDc model calibration/validation}

The MISDc model was calibrated and tested through its capability to simulate discharge for the two river sections of Santa Lucia and Ponte Felcino. To this end, the study period was divided into two parts: from 2000 to 2005 for model parameter calibration and from 2006 to 2010 for model validation. As objective functions, the Nash-Sutcliffe efficiency (NSE) (Nash and Sutcliffe, 1970), the NSE adapted to high flow conditions (ANSE) (Hoffmann et al., 2004), and the determination coefficient $R^{2}$ were used for model validation. Figure 3 shows the model results for the Santa Lucia river section in the calibration and validation period (similar findings are observed for the Ponte Felcino river section). The agreement between observed and modelled discharge is quite good, both in the calibration and validation periods, with NSE values greater than 0.75 and 0.83 for Santa Lucia and Ponte Felcino, respectively (see Table 1).
In particular, the model was found reliable in reproducing both the peak and the shape of the observed hydrographs, mainly during high flow conditions that are of much interest for the implementation of the RR-DB (see ANSE values in Table 1). The unexpected better performance of the model in the validation period, mainly for Santa Lucia, is dependent on the higher variability of discharge in that period that facilitates the achievement of higher performance score. For highlighting the MISDc performance during flood events, Fig. 4 shows the model results for the four largest floods occurred in the study period: December 2000, November 2005, December 2008 and January 2010. The good results of the hydrological model confirm the selection for its use within the RR-DB.

In addition, the capability of the MISDc model to predict extreme discharge conditions was assessed by coupling the rainfall-runoff model with the rainfall and temperature stochastic generator. Therefore, the frequency of annual maximum discharge, i.e., the flood frequency, for the two basins is compared with observed data. Figure 5 shows the flood frequency curves from observed ( $28 \mathrm{yr}$ of annual peak discharges) and simulated (500 yr) annual maximum discharges for the Ponte Felcino river section. In accordance with a previous study in the same study area (Camici et al., 


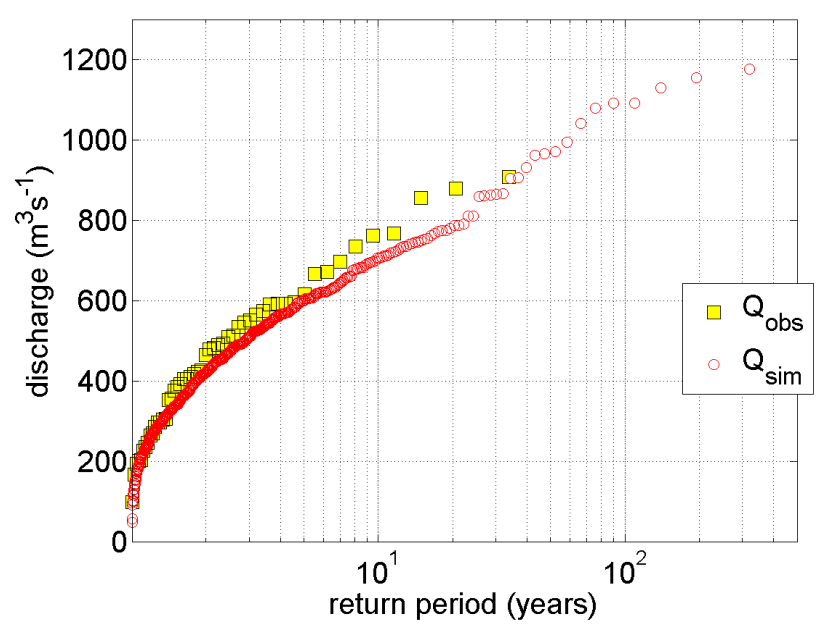

Fig. 5. Frequency distribution of annual maximum discharges obtained from the observed, $Q_{\mathrm{obs}}$, and simulated, $Q_{\text {sim }}$, data for the Ponte Felcino river section.

2011), a fairly good agreement with observations is obtained, thus allowing the assumption that the proposed procedure could also be able to reproduce extreme discharge conditions.

\subsection{Precondition table}

Based on the simulation of the rainfall-runoff model, the classes of antecedent wetness condition, AWC, and discharge, $Q$, of the two river basins were identified. Specifically, AWC values range between 0.24 and 0.98 with a step of 0.02 and $Q$ values between 0 and $200 \mathrm{~m}^{3} \mathrm{~s}^{-1}$ with step of $10 \mathrm{~m}^{3} \mathrm{~s}^{-1}$ (see Table 2).

Successively, the $k$ means cluster analysis was applied to identify the AWC ranges that correspond to season-specific $Q$ values. While the initial discharge is known as it is observed at the gauging station, AWC values are usually not known. Therefore, initial AWC ranges are derived from the discharge range for each month of the year using Table 3 . In this study, 12 clusters are considered and an example for three months and for Santa Lucia river section is reported in Table 3. From this table, the saturation intervals corresponding to specific $Q$ values of a particular month can be easily identified. This helps to limit the number of streamflow simulations selected by a database query implemented in SQL (Structured Query Language), see below.

It is worth noting that instead of computing the AWC values as a function of discharge, initial soil moisture conditions can be also obtained by in situ and/or remote sensing data (e.g. Brocca et al., 2010; Matgen et al., 2012) and/or by continuously applying the rainfall-runoff model that requires continuous and real-time rainfall and temperature data. These further options will be investigated in a future study.
Table 2. Number of rainfall-runoff scenarios and model initialization states within the RR-DB.

\begin{tabular}{lrrrr}
\hline & MIN & MAX & STEP & $\#$ \\
\hline AWC $[-]$ & 0.24 & 0.98 & 0.02 & 38 \\
$Q\left[\mathrm{~m}^{3} \mathrm{~s}^{-1}\right]$ & 0 & 200 & 10 & 21 \\
Rainfall-temperature scenarios & & 10000 \\
\hline Runoff scenarios & & & 7980000 \\
\hline
\end{tabular}

\section{Application of the rainfall-runoff database}

The calibration and analysis of the different models/tools employed in developing the RR-DB was described in the previous section. Once the framework of the RR-DB has been implemented, its application is rather easy and does not require specific hydrological modelling skills.

By way of example we consider the outlet of basin at Santa Lucia. Let us assume the month is January and, for a scheduled time, the rainfall forecast for the next $24 \mathrm{~h}$ is $40 \mathrm{~mm}$ and the actual discharge at Santa Lucia is $24 \mathrm{~m}^{3} \mathrm{~s}^{-1}$. Considering the precondition table (Table 3), in terms of $Q_{0}$ the interval of interest is $20.28-29.65 \mathrm{~m}^{3} \mathrm{~s}^{-1}$, corresponding AWC0 values ranging between 0.852 and 0.884 (according to the seasonal classification for January), and rainfall scenarios are selected in the range $\pm 10 \%$ (36 to $44 \mathrm{~mm}$ ) from the expected value $(40 \mathrm{~mm})$. Based on SQL, the query is formulated as follows:

SELECT all runoff simulations FROM runoff simulation table that were generated based on rainfall scenarios $>=36$ AND $<=44 \mathrm{~mm}$ AND were started with $Q_{0}$ values $>=20.28$ AND $<=29.65 \mathrm{~m}^{3} \mathrm{~s}^{-1}$ AND AWC $_{0}$ values $>=0.852$ AND $<=0.884$.

A result set of runoff simulations will be obtained that represents the runoff forecasts for the gauge.

The approach is tested for the two sub-basins of the Upper Tiber River considering the three largest flood events occurred in the study period (2005, 2008 and 2010). In order to test the database capability of capturing the four flood events, it was necessary to create SQL queries for each event according to observations and forecasts. It is a hindcast application of the database where we assume observed rainfall during the flood events to be the weather forecast. Figure 6 shows the comparison between the observed discharge and the ensemble generated through the application of the RR-DB for the two basins. Graphs show the ensemble containing $90 \%$ and $50 \%$ of all simulations matching the SQL queries. The two ensembles are obtained by cutting off the $5 \%$ and $25 \%$ percentiles from the lower and upper parts of the result sets. In principle, the ensemble should determine the uncertainty band of the flood simulation due to the different rainfall patterns on the one hand, and due to the initial condition values, mainly the antecedent wetness conditions of the basin (Brocca et al., 2008a; Camici et al., 2011) on the other hand. We note that the initial time step for the hydrographs was selected in a consistent way for historical and generated events, 
Table 3. Example of the precondition table obtained through the $k$ means cluster analysis for Santa Lucia river section and for the months of January, April and September (AWC: Antecedent Wetness Conditions, $Q$ : discharge).

\begin{tabular}{|c|c|c|c|c|c|c|}
\hline Clusters & AWC range & $Q$ range & AWC range & $Q$ range & AWC range & $Q$ range \\
\hline \multicolumn{3}{|c|}{ January } & \multicolumn{2}{|c|}{ April } & \multicolumn{2}{|c|}{ September } \\
\hline 1 & $0.665-0.846$ & $0-2$ & $0.664-0.802$ & $0-1$ & $0.289-0.355$ & $0-0$ \\
\hline 2 & $0.799-0.846$ & $2-4$ & $0.782-0.817$ & $1-2$ & $0.366-0.400$ & $0-0$ \\
\hline 3 & $0.818-0.851$ & $4-8$ & $0.802-0.832$ & $2-4$ & $0.400-0.429$ & $0-0$ \\
\hline 4 & $0.831-0.867$ & $8-13$ & $0.815-0.844$ & $4-6$ & $0.429-0.460$ & $0-0$ \\
\hline 5 & $0.843-0.880$ & $13-20$ & $0.825-0.867$ & $6-9$ & $0.460-0.506$ & $0-0$ \\
\hline 6 & $0.852-0.884$ & $20-30$ & $0.834-0.875$ & $9-13$ & $0.506-0.588$ & $0-0$ \\
\hline 7 & $0.860-0.891$ & $30-43$ & $0.842-0.882$ & $13-17$ & $0.593-0.675$ & $0-0$ \\
\hline 8 & $0.868-0.898$ & $43-62$ & $0.848-0.888$ & $17-23$ & $0.675-0.803$ & $0-1$ \\
\hline 9 & $0.875-0.910$ & $62-91$ & $0.854-0.892$ & $23-31$ & $0.807-0.822$ & $1-3$ \\
\hline 10 & $0.878-0.925$ & $92-164$ & $0.860-0.894$ & $31-43$ & $0.809-0.827$ & $3-5$ \\
\hline 11 & $0.886-0.932$ & $172-290$ & $0.867-0.898$ & $44-63$ & $0.821-0.841$ & $5-8$ \\
\hline 12 & $0.898-0.933$ & $297-390$ & $0.876-0.897$ & $63-85$ & $0.832-0.847$ & $8-13$ \\
\hline
\end{tabular}
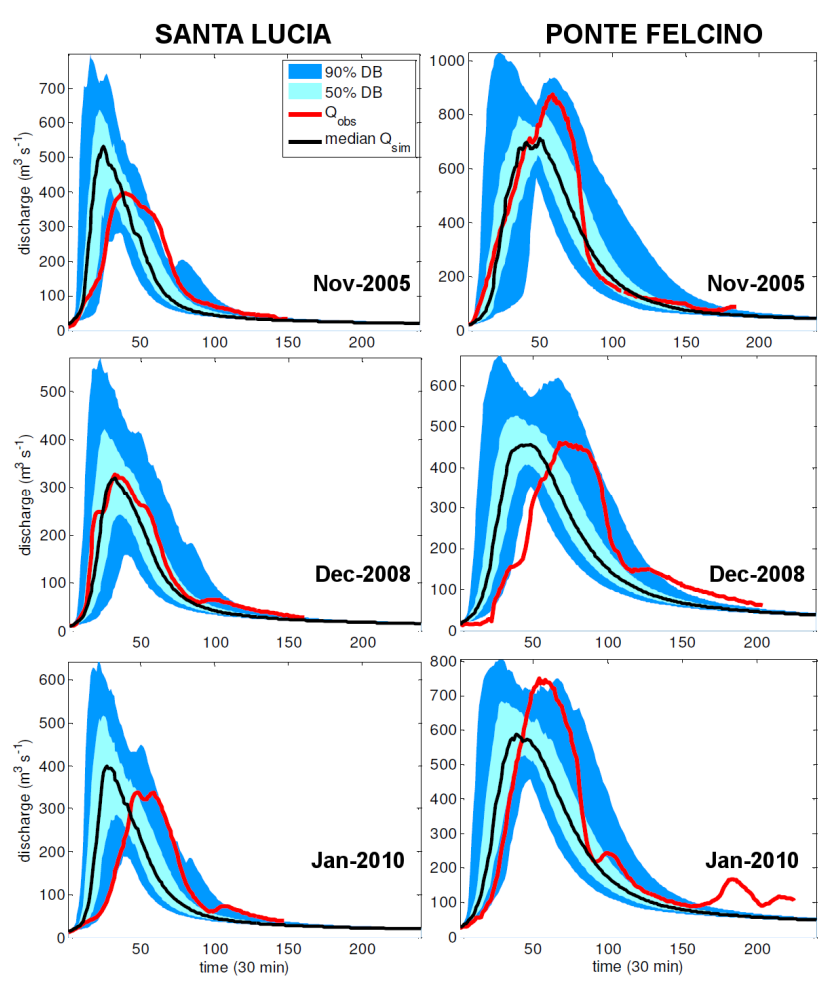

Fig. 6. Results of the rainfall-runoff (RR) database (DB) for the three largest flood events in the study period for Santa Lucia and Ponte Felcino river sections ( $Q_{\text {obs }}$ : observed discharge, median $Q_{\text {sim }}:$ median of simulated discharge through the RR-DB).

i.e., by considering the time when the rainfall starts. The results show that all flood events are captured by the $90 \%$ rainfall-runoff result set, except for a short period along the rising limb of the 2008 flood event at Ponte Felcino gauging station (see Fig. 6). For the event observed at Santa Lucia in 2008, a range between 170 and $560 \mathrm{~m}^{3} \mathrm{~s}^{-1}$ with an observed peak value of $\sim 300 \mathrm{~m}^{3} \mathrm{~s}^{-1}$ was found. Considering the $50 \%$ of the ensemble, the simulated range strongly reduces (240$400 \mathrm{~m}^{3} \mathrm{~s}^{-1}$ for the 2008 flood at Santa Lucia) even though, overall, a slight underestimation of the peak values was obtained for the floods of 2005 and 2010 at Ponte Felcino. By inspecting in-depth Fig. 6, for some floods it can be observed that the rising limb is anticipated (earlier) compared to the observed one. Considering the performance of the different components of the database, this drawback can be ascribed to the rainfall generator that usually produces rainfall scenarios starting before and that are shorter than the actual rainfall events. This issue can be solved by introducing a component for taking account of the actual temporal distribution of rainfall events into the stochastic rainfall generator. This aspect will be tested in a further study. However, considering the simplicity and the capability of reproducing quickly reliable flood scenarios with a lead time of $24 \mathrm{~h}$, the RR-DB is definitely of considerable interest as a tool of a flood forecasting systems.

For a preliminary quantitative assessment of the RRDB performance, a simple method based on the computation of the cumulative distribution function (CDF) of observed and simulated discharge is proposed as well. In fact, the simulated discharge from the database should be treated as synthetic data and, hence, the comparison between the CDFs of observed and simulated data is more appropriate than a time comparison (as shown in Fig. 6). Figure 7 shows the CDFs for observed and simulated data for the three flood events and for both river sections. The relative root mean square error (RRMSE) between observed and simulated (median) discharge is equal to $23.3 \%$ and $29.4 \%$ for Santa Lucia and Ponte Felcino river sections, respectively; these scores can be considered quite satisfactory. Moreover, the quantitative evaluation of the RRDB allowed us to identify the number of runs required to still yield satisfactory performance. For 

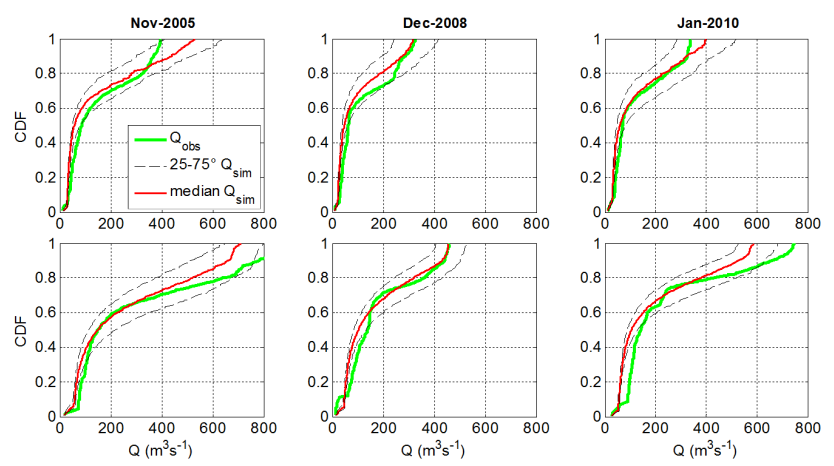

Fig. 7. Cumulative distribution function (CDF) for the observed and simulated discharge for Santa Lucia (upper panels) and Ponte Felcino (lower panels) river sections ( $Q_{\text {obs }}$ : observed discharge, 25$75^{\circ}$, median $Q_{\text {sim }}: 25-75$ percentiles and median of simulated discharge through the RR-DB).

that, $M$ rainfall events are randomly selected from the total number of events, with $M$ ranging between 100 and 10000 $(N=10000)$. For each subsample of the RRDB, and for the two investigated basins, the RRMSE is computed for the three flood events of 2005, 2008 and 2010. As a result, the database performance with $\sim 4000$ rainfall events is found to be very close to the one with the complete database.

\section{Conclusions}

Results of this study confirm the findings of other authors that simple approaches can succinctly represent the response of a catchment to precipitation (Jakeman et al., 1993; Kirchner, 2006; Perrin et al., 2007). Based on this principle, the proposed RR-DB might be an alternative to complex data- and parameter-intensive model frameworks for flood risk management.

The main benefits of the RR-DB can be thus identified: (1) it is open source and self-contained: no runs of RR models are required (only for the database development); (2) it is easy to use with the considerable advantage of getting as quickly as possible discharge scenarios for the following days and without requiring hydrologic modelling skills; but for the database development, modelling skills are required, of course; (3) it can be coupled with any hydraulic model providing the corresponding flooding scenarios; (4) due to the parsimonious approach to data requirements, it can be applied in many data-poor catchments; (5) uncertainties in rainfall measurements and forecasting as well as uncertainties relating to model predictions are implicitly taken into account.

By using database queries, one is able to produce flood risk scenarios depending on short-term rainfall forecasts. The database can be used by persons who are not familiar with hydrological modelling and one will retrieve the discharge hydrograph scenarios without having to run any kind of models with a considerable time saving to warning issues. Moreover, the possibility for the stakeholders involved in the FFS to have a direct control on the database (through queries) allows them to really trust the forecasting tool they are using.

The proposed procedure to develop a RR-DB can be applied to any catchment where good performance of discharge simulations can be achieved with a rainfall-runoff model. Due to the parsimonious parameterization of the model used and its minimal data requirements, runoff simulations can be performed very quickly on a standard PC. These are optimal conditions to realize thousands of simulations within a short period of time, thus embracing also the uncertainty associated to the model forecasts. In order to always provide fairly accurate flood scenario assessments, the database requires updating through novel flood events.

Further work should be dedicated to further improve the performance and usability of the proposed procedure. Specifically, the following modifications are foreseen: (1) introduction of a component for taking account of the actual temporal distribution of rainfall events into the stochastic rainfall generator, (2) addition of historical rainfall events in the database to improve the representativeness of the rainfall patters, (3) use of different rainfall-runoff models, (4) implementation of a real-time bias correction procedure (Brocca et al., 2010), and (5) use of satellite and/or in situ soil moisture observations for setting up the antecedent wetness conditions.

Acknowledgements. We would like to acknowledge the Umbria Region for providing the analyzed rainfall-runoff data. We are also grateful to P. Willems and one anonymous reviewer for their comments and suggestions. This work was partly funded by the POR-FESR Project, 2010,"Flooding Scenarios", Umbria Region. With this work we wish to memorialize co-author Florisa Melone, who passed away on 28 October, 2012. The only consolation we have is that we had the honor and privilege of working with her and had her in our life as colleague and mainly as friend.

Edited by: N. Verhoest

\section{References}

Asquith, W. H., Thompson, D. B., Cleveland, T. G., and Fang, X.: Synthesis of Rainfall and Runoff Data used for Texas Department of Transportation Research Projects 0-4193 and 0-4194, US Geological Survey, Open File Report 2004-103, p. 50, 2004.

Bae, D. H., Georgakakos, K. P., and Nanda, S. K.: Operational forecasting with real-time databases, J. Hydraul. Div.-ASCE, 121, 49-60, 1995.

Barbetta, S., Moramarco, T., Brocca, L., Franchini, M., and Melone, F.: Confidence interval of real-time forecast stages provided by the STAFOM-RCM model: the case study of the Tiber River (Italy), Hydrol. Process., online first, doi:10.1002/hyp.9613, 2012.

Berni, N., Brocca, L., Giustarini, L., Pandolfo, C., Stelluti, M., Melone, F., Moramarco, T.: Coupling hydrological and hydraulic modeling for a reliable flood risk mitigation activities 
in the Upper-Medium Tiber River basin, Geophys. Res. Abstr., EGU2009-9498-3, EGU General Assembly 2009, Vienna, Austria, 2009a.

Berni, N., Pandolfo, C., Ponziani, F., Stelluti, M., and Viterbo, A.: Umbria Region Forecasting/Decision Support fr Hydraulic Risk Mitigation Purposes, in: Proceedings of the Tenth International Conference on Computing and Control in the Water Industry, CRC Press, Sheffield (UK), 6 pp., 2009b.

Beven, K. J. and Binley, A. M.: The future of distributed models: model calibration and predictive uncertainty, Hydrol. Process., 6, 279-298, 1992.

Bras, R. L. and Rodriguez-Iturbe, I.: Random function and hydrology, Addison-Wesley Publishing Company, 1985.

Brocca, L., Melone, F., and Moramarco, T.: On the estimation of antecedent wetness conditions in rainfall-runoff modelling, Hydrol. Process., 22, 629-642, 2008a.

Brocca, L., Melone, F., Moramarco, T., and Singh, V. P.: A continuous rainfall-runoff model as tool for the critical hydrological scenario assessment in natural channels, in: Taniguchi, M., Burnett, W. C., Fukushima, Y., Haigh, M., and Umezawa, Y., From headwater to the ocean. Hydrological changes and managements, Taylor \& Francis Group, London, 175-179, 2008b.

Brocca, L., Melone, F., Moramarco, T., and Singh, V. P.: Assimilation of observed soil moisture data in storm rainfall-runoff modelling, J. Hydrol. Eng., 14, 153-165, 2009.

Brocca, L., Melone, F., Moramarco, T., Wagner, W., Naeimi, V., Bartalis, Z., and Hasenauer, S.: Improving runoff prediction through the assimilation of the ASCAT soil moisture product, Hydrol. Earth Syst. Sci., 14, 1881-1893, doi:10.5194/hess-141881-2010, 2010.

Brocca, L., Melone, F., and Moramarco, T.: Distributed rainfallrunoff modelling for flood frequency estimation and flood forecasting, Hydrol. Process., 25, 2801-2813, 2011a.

Brocca, L., Melone, F., Moramarco, T., Penna, D., Borga, M., Matgen, P., and Heitz, S.: Investigation of the hydrologic response of three experimental basins across Europe, Journal for Land Management, Food and Environment, 62, 31-37, $2011 \mathrm{~b}$.

Camici, S., Tarpanelli, A., Brocca, L., Melone, F., and Moramarco, T.: "Design soil moisture" estimation by comparing continuous and storm-based rainfall-runoff modelling, Water Resour. Res., 47, W05527, doi:10.1029/2010WR009298, 2011.

Chao, Z., Hua-sheng, H., Wei-min, B., and Luo-ping, Z.: Robust recursive estimation of auto-regressive updating model parameters for real-time flood forecasting, J. Hydrol., 349, 376-382, 2008.

Cloke, H. and Pappenberger, F.: Ensemble flood forecasting: A review, J. Hydrol., 375, 613-626, 2009.

Cowpertwait, P. S. P.: Further developments of the Neyman-Scott clustered point process for modelling rainfall, Water Resour. Res., 27, 1431-1438, 1991a.

Cowpertwait, P. S. P.: The stochastic generation of rainfall time series, Ph.D. Thesis, University of Newcastle upon Tyne, 1991b.

Cowpertwait, P. S. P., O'Connell, P. E., Metcalfe, A. V., and Mawdsley, J. A.: Stochastic point process modelling of rainfall. I. Single-site fitting and validation, J. Hydrol., 175, 17-46, 1996.

Damle, C. and Yalcin, A.: Flood prediction using Time Series Data Mining, J. Hydrol., 333, 305-316, 2007.

de Roo, A. P. J., Gouweleeuw, B., Thielen, J., Bartholmes, J., Bongioannini-Cerlini, P., Todini, E., Bates, P. D., Horritt, M., Hunter, N., Beven, K., Pappenberger, F., Heise, E., Rivin, G.,
Hils, M., Hollingsworth, A., Holst, B., Kwadijk, J., Reggiani, P., Van Dijk, M., Sattler, K., and Sprokkereef, E.: Development of a European flood forecasting system, Int. J. River Basin Manage., 1, 49-59, 2003.

Gabellani, S., Boni, G., Ferraris, L., von Hardenberg, J., and Provenzale, A.: Propagation of uncertainty from rainfall to runoff: A case study with a stochastic rainfall generator, Adv. Water Resour., 30, 2061-2071, 2007.

Georgakakos, K. P., Carpenter, T. M., Cramer, J. A., Sperfslage, J. A., Sweeney, T. L., and Fread, D. L.: National system for threshold runoff estimation, in: Engineering Hydrology, edited by: Kuo, C. Y., American Society of Civil Engineers, New York, 952-957, 1993.

Hartigan, J. and Wong, M.: Algorithm AS 136: A K-Means Clustering Algorithm, J. Roy. Stat. Soc. C-App., 28, 100-108, 1979.

Hashemi, A. M., Franchini, M., and O'Connell, P. E.: Climatic and basin factors affecting the flood frequency curve: PART I - A simple sensitivity analysis based on the continuous simulation approach, Hydrol. Earth Syst. Sci., 4, 463-482, doi:10.5194/hess-4-463-2000, 2000.

Hoffmann, L., Idrissi, A. E., Pfister, L., Hingray, B., Guex, F., Musy, A., Humbert, J., Drogue, G., and Leviandier, T.: Development of regionalized hydrological models in an area with short hydrological observation series, River Res. Appl., 20, 243-254, 2004.

Hurst, H. E.: Long-term storage capacity of reservoirs, T. Am. Soc. Eng., 116, 770-799, 1951.

Jakeman, A. J., Littlewood, I. G., and Whitehead, P. G.: Computation of the instantaneous unit hydrograph and identifiable component flows with application to two small upland catchments, J. Hydrol., 117, 275-300, 1993.

Kirchner, J. W.: Getting the right answers for the right reasons: Linking measurements, analyses, and models to advance the science of hydrology, Water Resour. Res., 42, W03S04, doi:10.1029/2005WR004362, 2006.

Krzysztofowicz, R.: Integrator of uncertainties for probabilistic river stage forecasting: precipitation-dependent model, J. Hydrol., 249, 69-85, 2001.

Liersch, S. and Volk, M.: A rainfall-runoff database to support flood risk management, in: Proceedings of the iEMSs Fourth Biennial Meeting: International Congress on Environmental Modelling and Software (iEMSs 2008), edited by: Sànchez-Marrè, M., Béjar, J., Comas, J., Rizzoli, A. E., and Guariso, G., International Environmental Modelling and Software Society, Barcelona, Catalonia, 494-502, 2008.

Matgen, P., Fenicia, F., Heitz, S., Plaza, D., de Keyser, R., Pauwels, V. R. N., Wagner, W., and Savenije, H.: Can ASCAT-derived soil wetness indices reduce predictive uncertainty in well-gauged areas? A comparison with in-situ soil moisture gauges in an assimilation application, Adv. Water Resour., 44, 49-65, 2012.

Montanari, A., Rosso, R., and Taqqu, M. S.: Fractionally differenced ARIMA models applied to hydrologic time series: identification, estimation and simulation, Water Resour. Res., 33, 10351044, 1997.

Moretti, G. and Montanari, A.: Inferring the flood frequency distribution for an ungauged basin using a spatially distributed rainfall-runoff model, Hydrol. Earth Syst. Sci., 12, 1141-1152, doi:10.5194/hess-12-1141-2008, 2008.

Nash, J. and Sutcliffe, J.: River flow forecasting through conceptual models, Part 1 - a discussion of principles, J. Hydrol., 10, 282- 
290, 1970.

Perrin, C., Oudin, L., Andreassian, V., Rojas-Serna, C., Michel, C., and Mathevet, T.: Impact of limited streamflow data on the efficiency and the parameters of rainfall-runoff models, Hydrolog. Sci. J., 52, 131-151, 2007.

Reggiani, P. and Weerts, A.: A Bayesian approach to decisionmaking under uncertainty: An application to real-time forecasting in the river Rhine, J. Hydrol., 356, 56-69, 2008.

Rodriguez-Iturbe, I., Febres De Power, B., and Valdes, J. B.: Rectangular pulses point process models for rainfall: analysis of empirical data, J. Geophys. Res., 92, 9645-9656, 1987.

Romanowicz, R. J., Young, P. C., Beven, K. J., and Pappenberger, F.: A data based mechanistic approach to nonlinear flood routing and adaptive flood level forecasting, Adv. Water Resour., 31, 10481056, 2008.

Smith, K. and Ward, R.: Floods: Physical Processes and Human Impacts, John Wiley, Chichester, 1998.

Tiwari, M. K. and Chatterjee, C.: Uncertainty assessment and ensemble flood forecasting using bootstrap based artificial neural networks (BANNs), J. Hydrol., 382, 20-33, 2010.
Van Steenbergen, N. and Willems, P.: Method for testing the accuracy of rainfall- runoff models in predicting peak flow changes due to rainfall changes, in a climate changing context, J. Hydrol., 414-415, 425-434, 2012.

Vaze, J., Post, D. A., Chiew, F. H. S., Perraud, J. M., Viney, N. R., and Teng, J.: Climate nonstationarity - Validity of calibrated rainfall-runoff models for use in climatic change studies, J. Hydrol., 394, 447-457, 2010.

Villarini, G., Krajewski, W. F., Ntelekos, A. A., Georgakakos, K. P., and Smith, J. A.: Towards probabilistic forecasting of flash floods: the combined effects of uncertainty in radar-rainfall and flash flood guidance, J. Hydrol., 394, 275-284, 2010.

Werner, M., Reggiani, P., De Roo, A., Bates, P., and Sprokkereef, E.: Flood forecasting and warning at the River Basin and at the European Scale, Natural Hazards, 36, 25-42, 2005. 